\title{
A comparative analysis of the postural and diurnal ocular perfusion pressure of young healthy individuals of different ethnicities
}

\begin{tabular}{|c|c|}
\hline $\begin{array}{l}\text { Authors: } \\
\text { Alvin J. Munsa } \\
\text { Kelisha Gopau } \\
\text { Kimesha Peru } \\
\text { Muhammad } \\
\text { Luvuyo Bidla }{ }^{1} \\
\text { Twapewa L. SI } \\
\text { Bongeka Vilak }\end{array}$ & $\begin{array}{l}\text { my }^{1} \\
\text { l1 }^{1} \\
\text { naul }^{1} \\
\text { 1. Moosa } \\
\text { aetonhodi }^{1} \\
\text { azi }^{1}\end{array}$ \\
\hline \multicolumn{2}{|c|}{$\begin{array}{l}\text { Affiliations: } \\
\text { Discipline of Optometry, } \\
\text { University of KwaZulu-Natal, } \\
\text { South Africa }\end{array}$} \\
\hline \multicolumn{2}{|c|}{$\begin{array}{l}\text { Corresponding author: } \\
\text { Alvin Munsamy, } \\
\text { munsamya1@ukzn.ac.za }\end{array}$} \\
\hline \multicolumn{2}{|c|}{$\begin{array}{l}\text { Received: } 21 \text { Sept. } 2017 \\
\text { Accepted: } 22 \text { Mar. } 2018 \\
\text { Published: } 14 \text { June } 2018\end{array}$} \\
\hline \multicolumn{2}{|c|}{$\begin{array}{l}\text { How to cite this article: } \\
\text { Munsamy AJ, Gopaul K, } \\
\text { Perumaul K, et al. A } \\
\text { comparative analysis of the } \\
\text { postural and diurnal ocular } \\
\text { perfusion pressure of young } \\
\text { healthy individuals of } \\
\text { different ethnicities. Afr } \\
\text { Vision Eye Health. 2018; } \\
77(1) \text {, a427. https://doi.org/ } \\
\text { 10.4102/aveh.v77i1.427 }\end{array}$} \\
\hline \multicolumn{2}{|c|}{$\begin{array}{l}\text { Copyright: } \\
\text { (c) 2018. The Author(s). } \\
\text { Licensee: AOSIS. This work } \\
\text { is licensed under the } \\
\text { Creative Commons } \\
\text { Attribution License. }\end{array}$} \\
\hline \multicolumn{2}{|l|}{ Read online: } \\
\hline 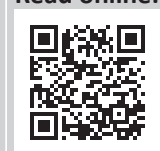 & $\begin{array}{l}\text { Scan this QR } \\
\text { code with your } \\
\text { smart phone or } \\
\text { mobile device } \\
\text { to read online. }\end{array}$ \\
\hline
\end{tabular}

Purpose: Ocular perfusion pressure (OPP) regulates the flow of blood to the optic nerve and is determined by the interaction between intraocular pressure (IOP) and blood pressure (BP). Low OPP increases the incidence of primary open-angle glaucoma (POAG). The aim is to compare the diurnal (i.e. morning vs. afternoon) and postural (i.e. seated vs. supine) OPP in healthy individuals from different ethnicities aged between 18 and 30 years.

Methodology: Averaged IOP and BP measurements were obtained with an ICare rebound tonometer and an automated sphygmomanometer, respectively. Measurements were taken in the morning and afternoon, in the supine and seated positions in healthy young adults: Africans $(n=10)$, white people $(n=10)$, mixed-race people $(n=10)$ and Indians $(n=10)$.

Results: The whole sample $(N=40)$ displayed a statistically significant reduction in postural and diurnal OPP both in the supine position and in the morning, respectively. A comparative analysis revealed that Africans displayed statistically significant reduction in OPP when compared to other ethnicities.

Discussion: A change in posture to the supine position has a greater impact on the reduction of OPP when compared to diurnal changes. Africans displayed clinically significant reduction in OPP which may increase the incidence of POAG in this ethnicity at an early age.

Conclusion: Our findings question whether OPP should be considered as a biomarker in the dark-skinned individuals. An evaluation of BP and IOP in the supine position is recommended for all patients to obtain more conclusive readings.

\section{Introduction}

Glaucoma has been identified as the second leading cause of blindness worldwide after cataracts. ${ }^{1}$ Extensive research has suggested an association between vascular risk factors and glaucoma. . $3,4^{3}$ Although intraocular pressure (IOP) remains a significant risk factor for glaucoma, studies have noted that arterial blood pressure (BP) can also influence the disease progression. ${ }^{4,5}$ Ocular perfusion pressure (OPP) regulates the flow of blood to the optic nerve and is determined by the interplay between IOP and BP. ${ }^{6}$ Considering the relationship between OPP and open-angle glaucoma (OAG) is multifaceted, the focus of this study was to compare the postural and diurnal aspects of OPP in healthy individuals of different ethnicities.

Universally, the perfusion pressure of an isolated organ is defined as the difference in pressure between its arterial and venous blood supply. ${ }^{7}$ Research has indicated that the venous pressure within the eye is approximately equivalent to the IOP; hence, OPP is measured as the difference between the arterial BP and IOP. ${ }^{4,8} \mathrm{OPP}$ can further be formulated as systolic OPP (SOPP), which is the difference between the systolic $\mathrm{BP}$ and $\mathrm{IOP}^{5}$, and diastolic OPP (DOPP), which is the difference between the diastolic BP and IOP. Mean OPP (MOPP) can be taken as the difference between two-thirds of the mean arterial pressure (MAP) and IOP, where the factor of two-thirds accounts for the difference in BP between the brachial and ophthalmic arteries. The difference between the systolic and diastolic BP is factored by one-third and then added to the diastolic BP to determine the MAP. ${ }^{5}$

In contrast to the abundance of literature arising from various epidemiological studies and clinical trials, only a few experimental studies have explored the combined effects of IOP and BP on ocular perfusion. ${ }^{4,8}$ The Baltimore Eye Study noted that only DOPP lower than $30 \mathrm{mmHg}$ portrayed the most clinical significance in the pathogenesis of glaucoma. ${ }^{9}$ Both the Barbados Eye Study and 
the Latino Eye Study disregarded the isolative importance of DOPP., ${ }^{4,8}$ The Barbados Eye Study noted that SOPP $\leq 98 \mathrm{mmHg}$, DOPP $\leq 53 \mathrm{mmHg}$ and MOPP $\leq 40 \mathrm{mmHg}$ were all associated with an increased risk of OAG. ${ }^{4}$ The Latino Eye Study similarly concluded that MOPP $\leq 50 \mathrm{mmHg}$, DOPP $\leq 40 \mathrm{mmHg}$ and $\mathrm{SOPP} \leq 80 \mathrm{mmHg}$ displayed a greater prevalence of OAG. ${ }^{8}$ It can be deduced that the measurement of OPP is vital in portraying the vascular state of the eye as a reduction in $\mathrm{BP}$ or an increase in IOP results in a decrease in the overall perfusion pressure which increases the susceptibility of the optic nerve to glaucomatous changes.

Diurnal variations (i.e. morning vs. afternoon) in IOP and $\mathrm{BP}$ are noted throughout the day. Lui et al. ${ }^{5}$ investigated the diurnal IOP (i.e. the average of morning and afternoon IOP) and BP patterns and noted that the mean diurnal IOP was significantly higher in patients with suspected primary open-angle glaucoma (POAG) as compared to normal individuals. ${ }^{5}$ The study also reported that the mean diurnal BP was significantly lower in glaucomatous patients as compared to age-matched normal participants. ${ }^{5}$ The increase in IOP is because of the increased episcleral venous pressure induced by the action of the supine posture impeding the outflow of aqueous humour from the anterior chamber observed during sleep at night noting a peak recording in the morning. ${ }^{10}$

Variations in IOP and BP are also attributed to changes in body posture which are highly significant and modifiable. Postural IOP and BP are denoted as measurements taken in both the seated and supine positions. ${ }^{5,11,12}$ In clinical practice, IOP is mostly measured in the seated position. However, higher readings were noted in the supine position because of an increase in the episcleral venous pressure. ${ }^{5}$ In contrast to IOP, BP is noted to be lower in the supine position, and thus, measurements in both the seated and supine positions are required to accurately predict postural IOP and BP fluctuations. ${ }^{13}$

Liu et al. ${ }^{5}$ reported that IOP increases in the supine position approximate $6 \mathrm{mmHg}$ in both normal and glaucomatous patients. In addition to an increase in IOP, postural changes can influence OPP through BP, as moving from the seated position to the supine position can result in a drop in systemic BP by $20 \mathrm{mmHg}-30 \mathrm{mmHg}$, which also leads to a decrease in ocular resistance. ${ }^{12}$ It can be deduced from these clinical studies that postural and diurnal variations should be accounted for during BP and IOP measurements to accurately identify those which are of concern.

The incidence of OAG was investigated in various epidemiological studies from different geographical locations. ${ }^{4,8,9}$ Leske et al. ${ }^{4}$ conducted the first population-based study that investigated the effects of OPP on the incidence of OAG in a sample of black descendants aged between 40 and 84 years. Leske et al. ${ }^{4}$ concluded after a clinical trial of 9 years that participants who displayed a reduced MOPP, SOPP and DOPP had a higher risk of OAG, with $61 \%$ of the sample diagnosed with OAG at the end of the trial. ${ }^{4}$ Rudnicka et al. ${ }^{14}$ concluded that black populations had the highest OAG prevalence at all ages. However, there has been a paucity in literature relating to the effects of OPP in healthy individuals of different ethnicities as many studies have included patients on treatment with anti-glaucomatous and/or anti-hypertensive drugs which affected the quantification of OPP., Siesky et al. ${ }^{15}$ reported that individuals of African descent have reduced ocular blood flow than those of European descent which increases their risk to POAG.

There is adequate evidence to indicate that diurnal and postural variations in IOP and BP have been implicated in the development of OAG. In particular, low BP and high IOP predispose one to low OPP which increases the likelihood of ischaemic stress. An improved understanding of these two risk factors and how they interact to produce OAG will help better target potential treatment strategies. South Africa's multiracial society affords opportunities to study whether any ethnicity has a greater predilection to reduced OPP; thus, the study aims to compare the diurnal and postural OPP in healthy individuals from different ethnicities between the ages of 18 and 30 years.

\section{Methodology}

The objective of the study was to compare the diurnal and postural OPP in young healthy adults of different races, using an automated sphygmomanometer and the ICare rebound tonometer.

This is an observational, cross-sectional study. A purposive sampling technique was used to determine the eligibility of the participants for the study from the student population at the University of KwaZulu-Natal. The total sample size consisted of 40 participants, and this was determined using $F$-tests ANOVA on SPSS software version 24. Ten participants between the ages of 18 and 30 years from each race group (i.e. African people, white people, Indians and mixed-race people), whose body mass index (BMI) was in the normal range (i.e. 18.50-24.99), and who presented with no associated ocular and chronic systemic disorders, with no usage of chronic medication, were admitted into the study. The inclusion criteria specified that all participants were of South African Nationality ${ }^{16}$ and belonged to one of the four different race groups, as indicated by the participants. All participants were emmetropic or presented with low $(<0.50$ DS/DC) ametropia ${ }^{17}$ and were not recreational drug users or smokers. The study was conducted in the Discipline of Optometry, Eye clinic, University of KwaZulu-Natal, Westville campus.

\section{Instrumentation}

The automated sphygmomanometer and ICare rebound tonometer were found to be most effective and efficient in acquiring the diurnal measurements as a valid tool. ${ }^{18,19}$ The MicroLife automatic BP machine was used to measure BP and the ICareTA011 rebound tonometer was used to measure IOP. The ICare takes an average of six readings with a valid reading shown with ' $\mathrm{P}$ ' or ' $\mathrm{P}_{-}$', which indicates that the 
standard deviation of the different measurements has a slightly greater value than normal, but the effect on the result is unlikely to be relevant. Because of the above-mentioned mechanism, the ICare was shown to have inter-examiner reliability. ${ }^{20}$ The automatic sphygmomanometer displays systolic and diastolic BP, where an average of two BP measurements was taken one min apart with no greater than $5 \mathrm{mmHg}$ in difference to ensure reliability. ${ }^{21}$

\section{Study process}

The screening process for each participant included a case history, BMI calculation, direct ophthalmoscopy and/or fundus photography in order to meet the study's inclusion criteria. Body mass index was calculated as: $\frac{\text { Weight }(\mathrm{kg})}{\text { Height }(\mathrm{m})^{2}}$ and classified according to the table adapted from the World Health Organisation ${ }^{22}$ as an indicator of good health. A calibrated Hanson HX3019 Electronic Scale and a standard height stick were used to measure weight and height, respectively. The nationality of each participant was confirmed by checking their South African identification numbers and ensuring that the 11th number was a ' 0 '. This is to ensure that only individuals of a South African nationality were admitted into the study.

Data collection commenced with two sets of postural measurements (seated and supine) taken once in the morning between 06:00 and 11:00 and a second time in the afternoon between 14:00 and 18:00. ${ }^{21}$ The minimal time difference for morning versus afternoon measurements was 6 hours for participants. Kanadani et al. ${ }^{23}$ found that OPP was lowest in normal subjects around 12:00. Thus, morning and afternoon measurements were structured before and after 12:00. All procedures in both sessions were identical and began with a period of rest to ensure measurements were not contaminated by strenuous activity. ${ }^{24}$ Although measurements were being conducted, participants were instructed to relax, remain motionless and observe in silence. Intraocular pressure measurements were always followed by BP measurements.

\section{Supine measurements}

Supine measurements commenced with participants' supine for $5 \mathrm{~min} .{ }^{25}$ Supine IOP measurements were obtained by making the patient turn his or her head in the opposite direction to the eye being tested..$^{26}$ Supine BP measurements followed with the participants' hand rested beside them and the cuff correctly orientated and fastened over the left lower bicep just above the brachial artery.

\section{Seated measurements}

Seated measurements commenced after participants were seated upright for $5 \mathrm{~min} .{ }^{25}$ Seated IOP measurements were taken with the participant looking straight ahead. Seated BP measurements followed with the participants' left arm rested on a table beside them, aligned with their heart, and the cuff placed in the same position as stated above.

\section{Ocular perfusion pressure calculations}

The data collected were entered into the following formulae in order to calculate $\mathrm{OPP}^{27}$ :

$\mathrm{DOPP}=2 / 3 \mathrm{DBP}-\mathrm{IOP}$

$\mathrm{SOPP}=2 / 3 \mathrm{SBP}-\mathrm{IOP}$

$\mathrm{MOPP}=2 / 3(\mathrm{MAP}-\mathrm{IOP})$, where $\mathrm{MAP}=\mathrm{DBP}+1 / 3(\mathrm{SBP}-\mathrm{DBP})$

Systolic and diastolic BP measurements were taken as the average of two measurements. To ascertain the diurnal measurements, the MOPP, SOPP and DOPP were calculated for each participant in the morning and separately in the afternoon. To account for the postural measurements, the morning and afternoon calculations for MOPP, SOPP and DOPP were further separated into supine and seated measurements.

\section{Ethical consideration}

Ethical permission was obtained from the Biomedical Research and Ethics Committee at the University of KwaZulu-Natal. All participants signed an informed consent form prior to commencement of the study. All researchers ensured that participant information was kept confidential.

\section{Results}

The study population comprised of 40 healthy university students, 20 males and 20 females, between the ages of 18 and 30 years with the mean age of the sample being 22 years. The 40 participants were sub-divided into 10 from each race group, namely Africans, Indians, mixed-race people and white people.

The IOP and BP measurements were obtained in the morning and afternoon at different postural positions of supine and seated to calculate the MOPP, DOPP and SOPP. The IOP measurements of the right eyes only were used for statistical analysis as no statistically significant difference was obtained between the IOP of the two eyes per participant. The comparison of IOP between the right and left eye was statistically insignificant, when seated and supine in the morning were $p=0.06$ and $p=0.47$, respectively, and in the afternoon, this was $p=0.59$ and $p=0.39$, respectively. Statistical analysis was performed using the Statistical Package for Social Science (SPSS) Version 24 at a 95\% confidence interval $(p<0.05)$ using Wilcoxon signed-rank test for non-parametric data.

\section{Analysis of diurnal changes from morning to afternoon}

The whole sample $(N=40)$, as illustrated in Table 1 , showed that the supine mean MOPP, DOPP and SOPP values had a mean increase in the afternoon measurements when compared to the morning measurements; however, these results were not statistically significant. In the seated position, the mean MOPP, DOPP and SOPP measurements also showed a mean increase in the morning measurements when 


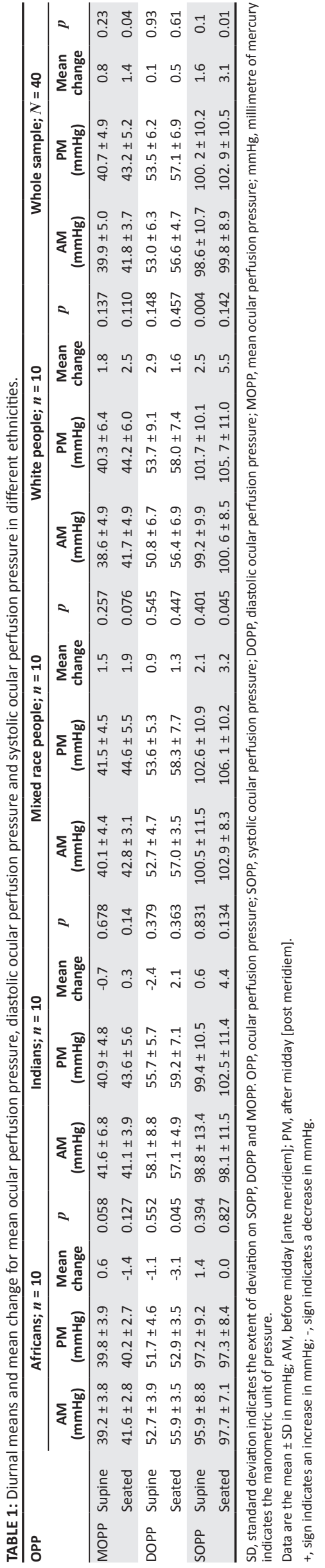

compared to the afternoon measurements, with only the diurnal seated MOPP and SOPP being statistically significant with $p=0.04$ and $p=0.01$, respectively.

The sample of Africans $(n=10)$, as illustrated in Table 1, showed that the supine mean MOPP and SOPP measurements had a mean increase in the afternoon measurements compared to the morning measurements, and supine mean DOPP showed a mean decrease in the afternoon measurements compared to the morning measurements; however, these results were all not statistically significant. In the seated position, the mean MOPP, DOPP and SOPP measurements also showed a mean decrease in the afternoon measurements when compared to the morning measurements, with only the diurnal seated DOPP being statistically significant at $p=0.045$.

The sample of mixed-race people $(n=10)$, as illustrated in Table 1, showed that both the supine and seated mean MOPP, DOPP and SOPP measurements having a mean increase in the afternoon from the morning, with only the diurnal seated SOPP being statistically significant at $p=0.045$.

The sample of Indians $(n=10)$, as illustrated in Table 1 , showed that the supine mean MOPP and DOPP measurements had a mean decrease in the afternoon measurements compared to the morning measurements, and supine SOPP showed a mean increase in the afternoon measurements compared to the morning measurements. In the seated position, the mean MOPP, DOPP and SOPP values all showed a mean increase in the afternoon measurements when compared to the morning measurements; however, all these results for the diurnal supine and seated analysis were not statistically significant.

The sample of white people $(n=10)$, as illustrated in Table 1 , showed that both the supine and seated mean MOPP, DOPP and SOPP measurements had a mean increase in the afternoon measurements when compared to the morning measurements, with only diurnal supine SOPP being statistically significant at $p=0.004$.

\section{Analysis of postural changes from seated to supine positions}

The whole sample $(N=40)$, as illustrated in Table 2, indicated that the morning and afternoon MOPP, DOPP and SOPP measurements displayed a mean increase in the seated position when compared to the supine position, with all comparisons being statistically significant except for the morning SOPP postural comparison.

The sample of Africans $(n=10)$, as illustrated in Table 2, showed that the morning and afternoon mean MOPP, DOPP and SOPP measurements had a mean increase in the seated position when compared to the supine position, with only the MOPP and DOPP postural comparison in the morning being statistically significant. 


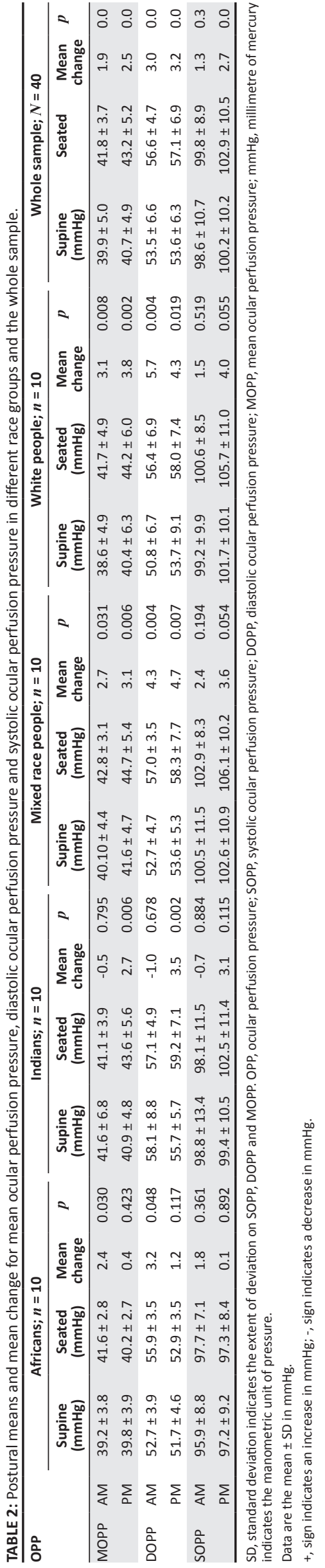

The sample of mixed-race people $(n=10)$, as illustrated in Table 2, showed that the morning and afternoon MOPP, DOPP and SOPP measurements had a mean increase in the seated position when compared to the supine position, with all except the postural morning and afternoon SOPP values being statistically significant.

The sample of Indians $(n=10)$, as illustrated in Table 2, showed that the morning mean MOPP, DOPP and SOPP measurements all had a mean decrease in the seated position when compared to the supine position; however, these findings were not statistically significant. In the afternoon, the mean MOPP, DOPP and SOPP measurements all showed a mean increase in the seated position when compared to the supine position, with only the afternoon MOPP and DOPP being statistically significant.

The sample of white people $(n=10)$, illustrated in Table 2 and Figures 1, 2 and 3, showed that the morning and afternoon mean MOPP, DOPP and SOPP measurements had a mean increase in the seated position when compared to the supine position, with all except the postural morning and afternoon SOPP measurements being statistically significant.

\section{Ethnicity comparison}

As shown in Table 3, and Figures 1, 2 and 3, the afternoon MOPP, DOPP and SOPP in the seated position for the African sample when compared to the mixed-race sample were statistically significant. The African sample in comparison had a lower OPP.

As shown in Table 3 and Figure 1, the afternoon SOPP measurements in the seated position for the African sample when compared to the white sample were statistically significant. The African sample in comparison displayed a lower OPP.

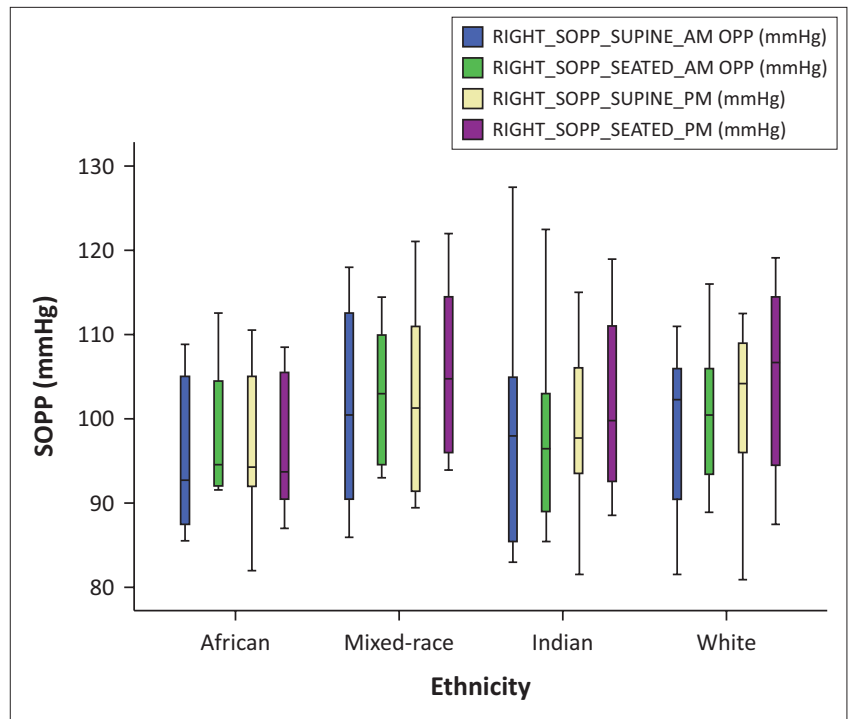

FIGURE 1: Box plot for systolic ocular perfusion pressure and different ethnicities in the seated and supine position in the morning and afternoon. 


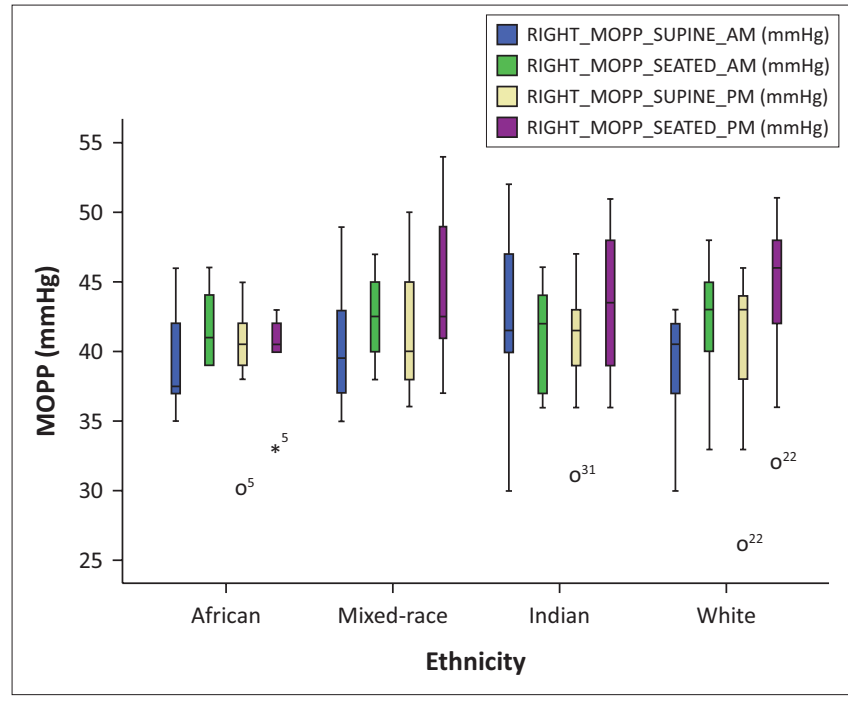

FIGURE 2: Box plot for mean ocular perfusion pressure and different ethnicities in the seated and supine position in the morning and afternoon.

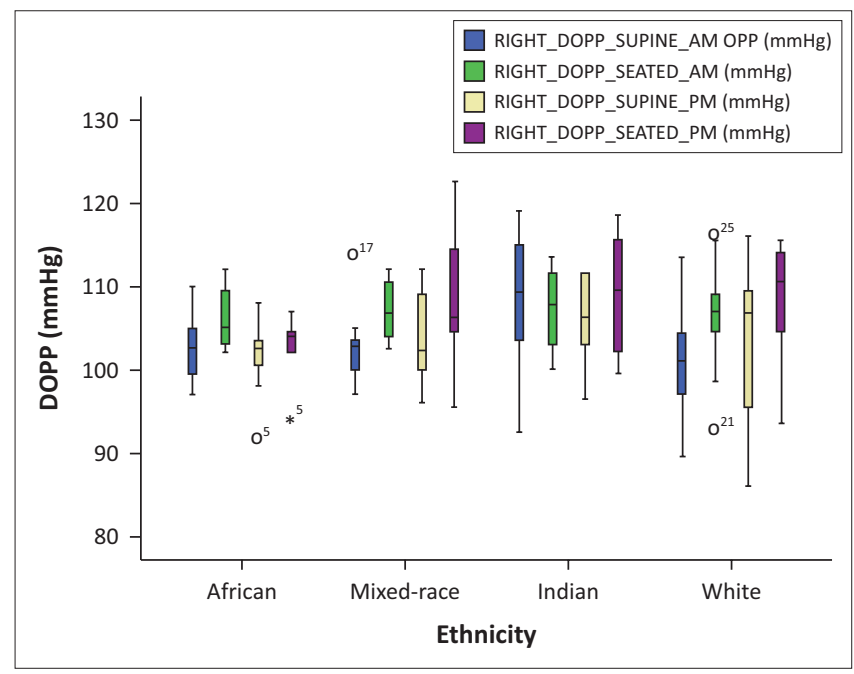

FIGURE 3: Box plot for diastolic ocular perfusion pressure and different ethnicities in the seated and supine position in the morning and afternoon.

TABLE 3: Wilcoxon signed-rank test, comparing different races at a $95 \%$ confidence interval.

\begin{tabular}{lllc}
\hline $\begin{array}{l}\text { thnicity } \\
\text { comparison }\end{array}$ & Observation & $\begin{array}{l}\text { Mean magnitude } \\
(\mathbf{m m H g})\end{array}$ & $p$ \\
\hline $\begin{array}{l}\text { African versus } \\
\text { mixed-race }\end{array}$ & $\begin{array}{l}\text { SOPP Seated PM } \\
\text { lower in Africans }\end{array}$ & SOPP(African) $=97.3 \pm 8.4$ & 0.028 \\
$\begin{array}{l}\text { African versus } \\
\text { white }\end{array}$ & $\begin{array}{l}\text { SOPP Seated PM } \\
\text { lower in Africans }\end{array}$ & SOPP(African) $=97.3 \pm 8.4$ & 0.008 \\
$\begin{array}{l}\text { African versus } \\
\text { mixed-race }\end{array}$ & $\begin{array}{l}\text { DOPP Seated PM } \\
\text { lower in Africans }\end{array}$ & DOPP(African) $=52.8 \pm 3.5$ & 0.021 \\
$\begin{array}{l}\text { African versus } \\
\text { mixed-race }\end{array}$ & $\begin{array}{l}\text { MOPP Seated PM } \\
\text { lower in Africans }\end{array}$ & MOPP(African) $=40.2 \pm 2.68$ & 0.012 \\
\hline $\begin{array}{l}\text { Indian versus white } \\
\text { DOPP Supine AM } \\
\text { lower in white people }\end{array}$ & DOPP(Indian) =58.1 \pm 8.8 & 0.041 \\
\hline
\end{tabular}

SOPP, systolic ocular perfusion pressure; DOPP, diastolic ocular perfusion pressure; MOPP, mean ocular perfusion pressure.

As shown in Table 3 and Figure 3, the morning DOPP measurements in the supine position for the Indian sample when compared to the white sample were statistically significant. The white sample in comparison had a lower OPP.

\section{Discussion}

To some extent, the effects of diurnal and postural variations on the measurements of IOP and BP in African, white, mixedrace and Indian ethnicities were evaluated. ${ }^{5,12}$ But BP and IOP measurements that have been investigated conventionally in the seated position at a single time interval are not sufficient because of the diurnal and postural changes that may occur.

The analysis of postural changes for the whole sample group revealed a statistically significant decrease in the MOPP, SOPP and DOPP from the seated to supine position in both morning and afternoon measurements as shown in Table 2. The decrease in the OPP in the supine position can be attributed to an increase in the IOP when supine as a result of an increase in the episcleral venous pressure. ${ }^{5}$ It may also be attributed to a reduction in BP which occurs when supine as a result of a drop in cardiac output. ${ }^{12}$ In comparison to the postural analysis, the diurnal analysis of the whole sample revealed clinically normal OPP, despite a statistically significant diurnal reduction in the morning, as shown in Table 1.

The sample displayed overall clinically reduced MOPP in the supine position when compared to the Barbados Eye Study. ${ }^{4}$ Our findings suggest that a change in posture has a greater impact on OPP than diurnal variations as a reduction in the MOPP whilst supine would be significant, particularly in atrisk glaucomatous individuals.

The analysis of postural changes for the sample of Africans revealed clinically reduced MOPP and DOPP in the supine position in the morning as shown in Table 2. These findings are in accordance with the Barbados Eye Study ${ }^{4}$ whose findings indicate that an MOPP of less than or equal to $40 \mathrm{mmHg}$ and a DOPP of less than or equal to $53 \mathrm{mmHg}$ increase the occurrence of POAG. Diurnally, the African sample presented with clinically reduced MOPP and DOPP in the afternoon with their respective findings also being in accordance with the Barbados Eye Study. ${ }^{4}$ Coupled with the postural analysis for this ethnicity, it is evident in this sample that OPP is impacted both posturally and diurnally at ages younger than 30 years. The eventual increase in the prevalence of POAG at ages older than 40 years does reinforce the role of perfusion as a risk factor.

The comparative analysis of the sample of Africans to the sample of mixed-race people and white people using the Wilcoxon signed-rank test revealed significant comparisons, as shown in Table 3. The sample of Africans displayed clinically reduced seated MOPP, SOPP and DOPP in the afternoon when compared to the mixed-race sample, with their respective values regarded as clinically low when compared to the Barbados Eye Study and the Los Angeles Latino Eye Study. ${ }^{4,8}$ The sample of Africans displayed clinically reduced seated SOPP in the afternoon when compared to the white sample, with this value regarded as 
clinically reduced according to the Barbados Eye Study. ${ }^{4}$ Our findings therefore corroborate those of Siesky et al. ${ }^{15}$ as nonglaucomatous individuals of an African descent display reduced OPP which may be attributed to the overall reduction in ocular blood flow. The greatest prevalence of POAG occurs in the African population, ${ }^{28}$ and because our findings suggest that young, healthy individuals in the sample of Africans display reduced perfusion pressure when supine as well as significantly reduced perfusion pressure when compared to other young, healthy individuals of different races, this questions whether ocular perfusion should be considered as a biomarker in the African population as its impact may start at a younger age.

The analysis of postural changes for the sample of mixedrace people or white people, as shown in Table 2, revealed clinically reduced MOPP and DOPP in the supine position which is in accordance with the Barbados Eye Study. ${ }^{4}$ However, diurnal analysis of these two racial samples, as shown in Table 1, revealed clinically normal OPP which mirrored the findings obtained for the whole sample. This concluded that a postural change has a greater clinical impact on OPP than diurnal changes. It is important to reiterate that all these changes are with regard to young, healthy individuals with no ocular disorders; thus, our findings suggest that these individuals may be predisposed to reduce OPP whilst in the supine position. Comparatively, the mixedrace sample displayed normal DOPP and SOPP when compared to the sample of Africans, as shown in Table 3. Thus, our findings suggest that the mixed-race sample may display better perfusion when compared to the sample of Africans, which is suggestive in accordance with a population-based study which concluded that the prevalence of POAG was an intermediate between white and African samples. ${ }^{29}$

The sample of Indians presented was the only ethnicity which did not display any statistically significant diurnal variations, as shown in Table 1. Despite a postural reduction in the DOPP whilst supine, as shown in Table 2, the DOPP was regarded as clinically normal according to the Los Angeles Latino Eye Study, ${ }^{8}$ Barbados Eye Study ${ }^{4}$ and Baltimore Eye Study. ${ }^{9}$ A comparative analysis of the Indian sample and the white sample, as shown in Table 3, found that this sample displayed higher DOPP whilst supine in the morning, which indicates that the Indian race group may display overall better perfusion, thus decreasing their susceptibility to POAG.

\section{Conclusion}

Ocular perfusion does undergo both diurnal and postural variations in young, healthy individuals. However, our findings suggest that a change in posture from seated to supine has a greater impact on the reduction of the overall perfusion pressure when compared to diurnal changes, as more statistically significant and clinically significant findings were noted whilst supine. In general, it is important to note that all these changes are occurring in a young, healthy, non-clinical sample. The sample of Africans displayed a clinically significant reduction in OPP whilst supine and in the afternoon. Africans may also display lower perfusion pressures in a sample younger than 30 years of age when compared to other ethnicities. Considering that this ethnicity has an increased susceptibility to POAG at an older age and that its impact may start at a younger age, our findings explore the role of perfusion as a risk factor which questions whether OPP should be considered as a biomarker in Africans. An increase in the sample size between ethnicities would increase the statistical power of future studies in this area. An hourly assessment of systemic BP and IOP should also be considered to enhance the accuracy of diurnal findings. Recommendations for the future studies include an evaluation of OPP as a biomarker in the glaucomatous population. Practitioners should also consider assessing IOP together with BP in the supine position in patients at risk for glaucomatous changes as well as in first degree relatives of glaucomatous patients. Supine OPP should be considered in at-risk glaucoma suspects.

\section{Acknowledgements}

The authors would like to acknowledge their statisticians, Dr W. Sibanda, Prof. P. Brown and Mr. P. Tinarwo, for their assistance.

\section{Competing interests}

The authors declare that they have no financial or personal relationships which may have inappropriately influenced them in writing this article.

\section{Authors' contributions}

A.J.M. was the project facilitator and supervisor. K.G., K.P., M.M.M., L.B., T.L.S. and B.V. all contributed towards the introduction, the literature review, research study and design, as well as the final research presentation.

\section{Funding information}

The authors' thank the African Vision and Research Institute for financial assistance with publishing page fees.

\section{References}

1. Congdon NG, Friedman DS. Important causes of visual impairment in the world today. JAMA. 2003;290(15):2057-2060. https://doi.org/10.1001/jama.290.15.2057

2. Sperber GO, Bill A. Blood flow and glucose consumption in the optic nerve, retina and brain: Effects of high intraocular pressure. Exp Eye Res. 1985;41(5):639-653. https://doi.org/10.1016/0014-4835(85)90036-3

3. Bonomi L, Marchini G, Marraffa M, et al. Vascular risk factors for primary open angle Glaucoma: The Egna-Neumarkt study. Ophthalmology. 2000;107(7): 1287-1293. https://doi.org/10.1016/S0161-6420(00)00138-X

4. Leske MC, Wu SY, Hennis A, Honkanen R, Nemesure B, BESs Study Group. Risk factors for incident open-angle glaucoma. The Barbados Eye Studies. Ophthalmology.2008;115(1):85-93. https://doi.org/10.1016/j.ophtha.2007.03.017

5. Liu JHK, Zhang $X$, Kripke DF, et al. Twenty-four-hour intraocular pressure pattern associated with early glaucomatous changes. Invest Ophthalmol Vis Sci. 2003;44(4):1586-1590. https://doi.org/10.1167/iovs.02-0666 
6. Feke GT, Rizzo JF 3rd. Regulation of retinal and optic nerve blood flow. Arch Ophthalmol [serial online]. 1999:117(7):979. [cited 2016 Apr 13]. Available from: http://www.ncbi.nlm.nih.gov/pubmed/10408474

7. Costa VP, Harris A, Anderson D, et al. Ocular perfusion pressure in glaucoma. Acta Ophthalmol. 2014;92(4):252-266. https://doi.org/10.1111/aos.12298

8. Memarzadeh F, Ying-lai M, Chung J, et al. Glaucoma : The Los Angeles Latino Eye Study. 2010;51(6):2872-2877. https://doi.org/10.1167/iovs.08-2956

9. Tielsch JM. The Baltimore Eye study. Am J Epidemiol [serial online]. 1991 134(10):1102-1110. [cited 2016 Apr 05]. Available from: http://www.ncbi.nlm. nih.gov/pubmed/2056646

10. Edward Chu HA. IOP goes 'Bump' in the night [homepage on the Internet]. April 5 2011. [cited 2015 Sept 04]. Available from: http://www.reviewofoptometry.com/ content/c/27571

11. Buys $Y M$, Alasbali $T$, Jin $Y P$, et al. Effect of sleeping in a head-up position on intraocular pressure in patients with glaucoma. Ophthalmology. 2010; 117(7):1348-1351. https://doi.org/10.1016/j.ophtha.2009.11.015

12. Schmidl D, Garhofer G, Schmetterer L. The complex interaction between ocular perfusion pressure and ocular blood flow - Relevance for glaucoma. Exp Eye Res. 2011;93(2):141-155. https://doi.org/10.1016/j.exer.2010.09.002

13. Fogagnolo $P$, Orzalesi $N$, Ferreras $A$, et al. The circadian curve of intraocular pressure: Can we estimate its characteristics during office hours? Inves Ophthalmol Vis Sci. 2009;50(5):2209-2215. https://doi.org/10.1167/iovs.08-2889

14. Rudnicka AR, Mt.-Isa S, Owen CG, et al. Variations in primary open-angle glaucoma prevalence by age, gender, and race: A Bayesian meta-analysis. Invest Ophthalmo prevalence by age, gender, and race: A Bayesian meta-analysis. Invest
Vis Sci. 2006;47(10):4254-4261. https://doi.org/10.1167/iovs.06-0299

15. Siesky B, Harris A, Amireskandari A, et al. Glaucoma and ocular blood flow: An anatomical perspective. Expert Rev Ophthalmol. 2012;7(4):325-340. https://doi. org/10.1586/eop.12.41

16. Evans AB. African Apartheid era - Identification of ID numbers. Afr Hist [serial online]. 2005. [cited 2016 Apr 10]. Available from: http://africanhistory.about.c/ library/bl/blldentityNumber.htm

17. Manny RE, Mitchell GL, Cotter SA, et al. Intraocular pressure, ethnicity, and refractive error. Optom Vis Sci. 2011;88(12):1. https://doi.org/10.1097/OPX.0b013e $318230 f 559$

18. Brusini $\mathrm{P}$, Salvetat ML, Zeppieri M, et al. Comparison of ICare tonometer with Goldmann applanation tonometer in glaucoma patients. J Glaucoma. 2006 15(3):213-217. https://doi.org/10.1097/01.ijg.0000212208.87523.66
19. Icare Finland Oy. Icare TA01i instruction manual. Vantaa, Finland: Icare Finland Oy; 2015.

20. Dahlmann-Noor AH, Puertas R, Tabasa-Lim S, et al. Comparison of handheld rebound tonometry with Goldmann applanation tonometry in children with glaucoma: A cohort study. BMJ Open. 2013;3(4):pii: e001788. https://doi.org/ 10.1136/bmjopen-2012-001788

21. Kurtz TW, Griffin KA, Bidani AK, et al. Recommendations for blood pressure measurement in humans and experimental animals. Hypertension. 2005;45(2): 299-310. https://doi.org/10.1161/01.hyp.0000150857.39919.cb

22. World Health Organization. WHO: Global database on body mass index [homepage on the Internet]. World Health Organization. [2016 Apr 13]. Available from: doi:papers3://publication/uuid/DF45B6E6-94B7-4B8A-97753A1313BA45EC

23. Kanadani FN, Moreira T, Bezerra B, et al. Diurnal curve of the ocular perfusion pressure. J Curr Glaucoma Pract. 2016;10(1):4-6. https://doi.org/10.5005/jpjournals-10008-1195

24. Sung KR, Lee S, Park SB, et al. Twenty-four hour ocular perfusion pressure fluctuation and risk of normal-tension glaucoma progression. Invest Ophthalmo Vis Sci. 2009;50(11):5266-5274. https://doi.org/10.1167/iovs.09-3716

25. Raman R, Gupta A, Kulothungan V, et al. Association of mean ocular perfusion pressure and diabetic retinopathy in type 2 diabetes mellitus: Sankara Nethralaya diabetic retinopathy epidemiology and molecular senetic study. Invest Ophthalmol Vis Sci. 2011;52(7):4592-4597. https://doi.org/10.1167/iovs. 10-6903

26. Lam $A, W u$ YF, Wong $L Y$, et al. IOP variations from sitting to supine postures determined by rebound tonometer. J Optom. 2013;6(2):95-100. https://doi.org/ 10.1016/j.optom.2012.12.002

27. Riva CE, Hero M, Titze P, et al. Autoregulation of human optic nerve head blood flow in response to acute changes in ocular perfusion pressure. Graefe's Arch Clin Exp Ophthalmol. 1997;235(10):618-626. https://doi.org/10.1007/ BF00946937

28. WHO. Glaucoma is second leading cause of blindness globally [homepage on the Internet]. WHO; 2011. [cited 2016 Oct 16]. Available from: http://www.who.int/ bulletin/volumes/82/11/feature1104/en/

29. Quigley HA, West SK, Rodriguez J, et al. The prevalence of glaucoma in a population-based study of Hispanic subjects: Proyecto VER. Arch Ophthalmol. 2001;119(12):1819-1826. https://doi.org/10.1001/archopht.119.12.1819 